\title{
COMUNICAÇÃO COMO FERRAMENTA GOVERNAMENTAL: QUESTÕES MIGRATÓRIAS NA FRANÇA
}

\author{
Communication as a governmental tool: migration issues in France
}

\section{Comunicación como herramienta gubernamental: cuestones migratorias en Francia}

Paula de Souza Paes

Professora Visitante do Programa de Pós-Graduação

em Jornalismo da UFPB

paulasouzapaes@gmail.com

\begin{abstract}
Resumo
Nossa proposta aborda a maneira pela qual as práticas de comunicação nacionais e locais, a partir dos anos 80, são ferramentas governamentais que ajudam na institucionalização do problema da imigração e na estigmatização de jovens franceses descendentes de imigrantes e de moradores de periferia. $\mathrm{O}$ artigo apresenta esse processo durante a presidência de Nicolas Sarkozy (2007-2012) na França. Para isso, analisa um caso específico de violência ocorrido em 2010 na Villeneuve, área residencial localizada na periferia de Grenoble, quando um grupo de moradores se confronta com a polícia após a morte de Karim Boudouda. O objetivo principal é demonstrar que o tratamento público da imigração visa localizar os "problemas" relacionados a esse tema, reforçando seus aspectos convencionais. Apresentada como expressão de abertura e de transparência do Estado em relação aos cidadãos, a comunicação pública em matéria de imigração manifesta, entretanto, a ação de regulação da esfera pública pelo Estado.
\end{abstract}

Palavras-chave: Comunicação pública. Imigração. Estigmatização.

\begin{abstract}
Our proposal addresses to the way in which national and local communication practices, starting in the 1980s, are governmental tools that institutionalize the problem of immigration and stigmatize young French descendants of immigrants and residents of the periphery. The article presents this process during the presidency of Nicolas Sarkozy (2007-2012) in France. To do so, it analyzes a specific case of violence in Villeneuve, a residential area on the suburb of Grenoble, in 2010, when a group of inhabitants confronts the police after the death of Karim Boudouda. the main objective is to demonstrate that the public treatment of immigration seeks to locate the "problems" related to this subject, reinforcing its conventional aspects. Presented as an expression of openness and transparency of the State in relation to citizens, the public communication on immigration, however, manifests the action of regulation of the public sphere by the State.
\end{abstract}

Key words: Public Communication. Immigration. Stigmatization. 


\section{Resumen}

Nuestra propuesta aborda la manera en que las prácticas de comunicación nacionales y locales, a partir de los años 80, son herramientas gubernamentales que ayudan en la institucionalización del problema de la inmigración y en la estigmatización de jóvenes franceses descendientes de inmigrantes y de habitantes de periferia. El artículo presenta este proceso durante la presidencia de Nicolas Sarkozy (2007-2012) en Francia. Para ello, analiza un caso específico de violencia ocurrido en 2010 en Villeneuve, área residencial ubicada en la periferia de Grenoble, cuando un grupo de vecinos se enfrenta a la policía tras la muerte de Karim Boudouda. El objetivo principal es demostrar que el tratamiento público de la inmigración busca localizar los "problemas" relacionados con ese tema, reforzando sus aspectos convencionales. Presentada como expresión de apertura y transparencia del Estado en relación a los ciudadanos, la comunicación pública en materia de inmigración manifiesta, sin embargo, la acción de regulación de la esfera pública por el Estado.

Palabras clave: Comunicación pública. Inmigración. Estigmatización.

\section{INTRODUÇÃO}

Este artigo é resultado de uma tese em ciências da informação e da comunicação que aborda à constituição do problema da imigração na França ao longo de 30 anos (1980-2010) (PAES, 2014). Nosso interesse pelo tema imigração tem a sua origem em 2007, quando muitas discussões sobre a questão dos imigrantes são realizadas através da mídia, no momento da eleição de Nicolas Sarkozy para a presidência da República. Em sua campanha presidencial, a imigração foi apresentada como uma questão de interesse público. Em uma conferência de imprensa, em 2006, Nicolas Sarkozy enfatizou: “[...] muitos franceses veem a imigração como uma ameaça à sua segurança, ao seu emprego, ao seu modo de vida [...] é nosso dever de lhes trazer uma resposta" (SARKOZY, 2006). De acordo com o candidato do partido tradicionalmente de direita, UMP (Union pour un mouvement populaire), a imigração causa problemas para os cidadãos franceses.

Em 2010, a posição política do chefe de Estado e de seu Governo sobre o tema imigração é realçado quando atos de violência envolvem a morte de um habitante de periferia na área residencial chamada Villeneuve, localizada nas áreas urbanas sensíveis na cidade de Grenoble $^{1}$. Em julho desse mesmo ano, um grupo de moradores de Villeneuve, uma área

\footnotetext{
${ }^{1}$ De acordo com a definição oficial, as Zonas Urbanas Sensíveis são territórios definidos pelos poderes públicos para serem o alvo prioritário da política urbana em função de considerações locais relativas às dificuldades que
} 
prioritária da política urbana em Grenoble, incendiaram carros e trocaram tiros com a polícia, após a morte de um jovem, Karim Boudouda, descendente de imigrantes e residente local. Ele havia sido baleado pela polícia após cometer um assalto em um cassino em Uriage (cidade perto de Grenoble). Durante sua visita a Grenoble no final de julho, o presidente propõe a retirada de cidadania dos indivíduos que cometerem crimes contra as forças de segurança. A Villeneuve é uma área residencial construída pela municipalidade socialista na década de 60 e 70 com o objetivo de favorecer o convívio de diferentes classes sociais, evitando assim a segregação social (JOLY; PARENT, 1988). Hoje, ela tem em torno de 12 mil habitantes².

Este artigo se justifica, portanto, pela curiosidade relacionada ao surgimento da questão da migração como uma questão prioritária durante o governo de Nicolas Sarkozy (2007-2010) e como ela é definida como um problema ou como uma questão que interessa os franceses. O objetivo principal é demonstrar que o tratamento público da imigração visa localizar o "problema" da imigração, reforçando os aspectos convencionais relacionados a esse problema. A comunicação pública em matéria de imigração manifesta a ação de regulação da esfera pública pelo Estado. Entretanto, ela é apresentada como expressão de abertura e de transparência do Estado em relação aos cidadãos (OLLIVIER-YANIV, 2000). No final da década de 1960, as atividades de comunicação desenvolveram e ganharam importância nas organizações públicas na França. Diretamente ligada ao serviço do aparelho estatal, a comunicação pública se desenvolveu com a preocupação de difundir e explicar as atividades dos poderes públicos aos cidadãos. Ela é apresentada como uma iniciativa de abertura, visando contribuir para o debate democrático e o funcionamento da esfera pública (Ollivier-Yaniv, 2006). Ela é tida, dessa forma, como "reflexo do interesse público". Sua definição é, portanto, atravessada por uma perspectiva normativa, que o presente artigo visa desconstruir.

Adotando uma perspectiva construtivista, em referência principalmente a Erik Neveu (1999), consideramos que um problema público não é "naturalmente” público. Dessa forma, o "problema" da imigração resulta de um trabalho de definição: da parte dos atores envolvidos, a partir dos questionamentos que emergem da sociedade e das respostas em termos de ação

enfrentam os habitantes desses territórios. "Les zones urbaines sensibles sont des territoires définis, par décret, par les pouvoirs publics comme des territoires prioritaires de la politique de la ville". Definição disponível: http://www.onzus.fr/presentation/les-quartiers-de-la-politique-de-la-ville consultado no dia 13 de janeiro de 2014. A lista das Zus conta com 751 territórios com 4,7 milhões de habitantes, sendo 7,5\% da população francesa.

2 Nós consultamos o sistema de informação geográfica da Secretaria geral do Comité Interministerial das Cidades). URL : http://sig.ville.gouv.fr, consultado no dia 22 de setembro de 2016. 
pública que são elaboradas em um determinado momento. No entanto, o surgimento de tal problema não é o resultado de ações conscientemente "calculadas". Ele aponta para uma relação de interdependência estabelecida entre indivíduos. Como afirma Norbert Elias (1975, p.98) em relação ao processo de civilização e a gênese do Estado, “o jogo de incontáveis ambições e interesses individuais - que eles sejam convergentes ou que se oponham - pode dar origem a um fenômeno que ninguém explicitamente queria ou programou, mas que, no entanto, deriva das ambições e ações de um grande número de indivíduos”. Consideramos, portanto, que os problemas públicos são fruto de um trabalho de definição por diferentes atores.

As modalidades para dar visibilidade a um "problema" é plural e dizem respeito a diferentes universos sociais, no entanto, a análise visa estudar especialmente os espaços políticos, mais especificamente o período em que Nicolas Sarkozy foi Presidente da República (2007-2012). Para isso, nossa análise se focaliza no caso de violência ocorrido na Villeneuve em 2010 citado acima. Entretanto, a fim de compreender as práticas de infocomunicacionais sobre a imigração nós estabelecemos, em primeiro lugar, um corpus com artigos de imprensa entre o período de 1985-2010³. Esse corpus de notícias permitiu repertoriar, a longo prazo, as práticas de informaçao e de comunicação e as estratégias de comunicação elaboradas pelo Estado sobre a questão imigração e a sua relação com os territórios. O termo estratégias é compreendido aqui no sentido elaborado por Pierre Bourdieu (2002). De acordo com o sociólogo, as estratégias são ações acordadas aos interesses dos atores e direcionadas para objetivos específicos. No entanto, essas ações não devem ser entendidas como ações determinadas para fins "expressamente concebidos" para alcançar um objetivo. Elas se referem a modos de luta, às relações de poder na produção de informações.

Foi constituído também um corpus que regrupa os comunicados de imprensa do Ministério do Interior durante o período de 1 ano, durante os incidentes ocorridos na

\footnotetext{
${ }^{3} \mathrm{O}$ corpus foi constituído a partir dos arquivos do jornal Le Monde, que a pesquisadora teve acesso em 2012, e os arquivos do museu chamado La Cité nationale de l'histoire de l'immigration (A cidade nacional da história da imigração). Consultamos jornais como: Le Monde, Le Figaro, Libération, La Croix, l'Humanité, e revista semanais : Le Nouvel Observateur, l'Express, Télérama, Le Point, Courrier international. Esse corpus estava classificado por temas, nós consultamos 4 : Política de imigração - debates políticos; Delinquência; Vida social violência urbana; Jovens - imigrantes jovens. Inaugurada em 2007, a Cité foi proposta pelo Programa de Ação Anual do Comitê Interministerial da Integração em abril de 2003. O objetivo era criar um centro de recursos multimídias e de memória da imigração, destacando o papel da imigração na construção do país. A Cité foi concebida como "um lugar de pedagogia, pesquisa, debate, tendo também uma função patrimonial". O que motivou sua criação foi a constatação da falta de um lugar na França que conserve a memória da imigração, como fazem outros países europeus. Hoje, a Cité se intitula apenas Museu da História da Imigração (Musée de l'histoire de l'immigration). Disponível em: http://www.histoire-immigration.fr. Acesso em: 22 de outubro de 2017.
} 
Villenueve (julho de 2010- julho de 2011). Na esfera local, nós consultamos o jornal de informação municipal chamado Les Nouvelles de Grenoble de 1999 a 2013. O objetivo era apreender a ação local em termos de política urbana e as informações publicadas sobre o bairro Villeneuve. O artigo apresenta uma análise do conteúdo desses diferentes materiais através de palavras-chaves como: "política de imigração"; "delinquência", "violências urbanas", “jovens imigrantes”. Foi possível perceber o posicionamento dos atores políticos em relação a esse tema e maneira pela qual ele é definido: de quem falamos quando é abordado a imigração enquanto problema? Quais explicações são mobilizadas pelas autoridades políticas? A metodologia empregada não se trata, portanto, de uma análise de discurso.

A análise foi complementada com entrevistas semi-dirigidas (34 no total) com jornalistas, agentes territoriais de Grenoble, o diretor de comunicação da prefeitura de Grenoble; a Prefeitura (ex-prefeito e oficiais da polícia - os diretores do Departamento de segurança pública) e associações de defesa dos direitos dos estrangeiros e imigrantes. Neste artigos, fazemos referência, entretanto, aos agentes territoriais que atuaram ou atuam na área da comunicação.

\section{Emergência das chamadas "violências urbanas" e o caso Villeneuve}

Durante o verão de 1981, jovens moradores da área residencial chamada Minguettes com forte concentração de população imigrante - provocam incidentes violentos, como incêndios de carros, lançamento de projétil e de cocktails Molotov contra a polícia (CHAMPAGNE, 1991, p. 67). Logo após esses atos de violência, o fluxo migratório para a França passa a ser associado publicamente pelos responsáveis políticos a temas como a

violência, a delinquência e a insegurança dos cidadãos franceses. É a partir dos incidentes em 1981 que a atenção, tanto das autoridades públicas quanto a dos jornalistas, focaliza-se nas famílias de imigrantes e os jovens que, frequentemente, estão desempregados ou em situação de dificuldade com os estudos.

Após a violência nos subúrbios de Lyon, outros atos violência aconteceram como, por exemplo, em Vaulx-en-Velin no final de 1990 e em outras cidades e bairros durante esse ano: em Argenteuil, Sartrouville, Mantes-la-Jolie e Montfermeil. Os incidentes se resumem a carros queimados e barricadas contra as forças policiais. 
No governo de François Mitterrand (1981-1995), durante todo o período dos anos 1980, algumas medidas são tomadas para resolver esse problema do "mal-estar" nos subúrbios, visando jovens filhos de imigrantes que moram em periferias. $\mathrm{O}$ governo lança dispositivos de inserção profissional de jovens; uma comissão pelo desenvolvimento social das periferias em 1981; a criação de um Conselho Nacional de prevenção da delinquência em 1982 e de uma Delegação interministerial pela inserção profissional e social dos jovens em dificuldade (LAFARGE, 2002, p. 6). Esses dispositivos desenvolvidos pelo governo logo após os incidentes em Lyon acabam ajudando a definir, aos poucos, os contornos do problema ligado aos imigrantes: as chamadas "violências urbanas". O governo realça as condições de vidas nessas áreas residenciais e a presença de imigrantes nesses locais, uma vez que direciona esses dispositivos aos jovens descendentes de imigrantes. Nesse sentido, localiza o tratamento da questão da imigração. O relatório elaborado pela Comissão nacional pelo desenvolvimento social das áreas residenciais em periferia ressalta que os problemas estão relacionados com a falta de coesão social entre os moradores (DUBEDOUT, 1983).

Duas pesquisas nos ajudam a entender esse processo de localização. A primeira é a realizada por Christine Barats (1994), que analisou os discursos do ex-presidente da República François Mitterrand (1981-1995) sobre a questão da imigração e da integração. Ela observa que, durante os primeiros anos do seu mandato, o Presidente intervém majoritariamente em países estrangeiros quando aborda o tema imigração. Entretanto, durante o período de 1984 a 1991, o território nacional se torna o lugar privilegiado de intervenção do Presidente para tratar esse tema. Esse movimento indica que a imigração não é mais entendida em termos de mobilidade, porque o movimento migratório é cada vez mais associado à integração dos estrangeiros no país.

A segunda pesquisa é a tese da socióloga Simone Bonnafous (1991) realizada nos anos 90 em que abordou o posicionamento de um conjunto de jornais em relação à imigração. Bonnafous analisa os discursos sobre imigração na imprensa nacional francesa de 1974 a 1984. Ela mostra que os artigos se concentram na descrição do ambiente de trabalho e de vida dos imigrantes nos anos de 1970. Os jornalistas informam sobre sua luta contra os empregadores e suas demandas por melhores condições de trabalho nas fábricas e de moradia. Os anos 1970 são marcados pela mobilização de trabalhadores estrangeiros na França.

A partir dos anos 80, ela percebeu a focalização dos artigos da imprensa no tema imigração se desloca das condições de vida e de trabalho dos imigrantes às dificuldades associadas à presença deles no país. A emergência, há 30 anos, do que a socióloga Annie 
Collovald (2001) chama de "problema das periferias" explica o deslocamento da produção de informação sobre a imigração. A percepção da imigração fora do quadro de trabalho ganha cada vez mais visibilidade, definindo os contornos do "problema da imigração": os indivíduos que estão em foco (os jovens imigrantes não-europeus) e os questionamentos que esse problema suscita (a delinquência, a insegurança e a dificuldade nas relações sociais com os franceses de pais franceses).

Nesse sentido, podemos afirmar que a maneira pela qual o "problema" é definido e legitimado (BERGER, LUCKMAN (1966), 2012, p. 162) está ligada às normas de comportamento (ELIAS, 1973, p. 135), às boas maneira e aos modos de vida dos franceses em relação aos imigrantes. Como afirma Norbert Elias sobre o processo da socio-gênese do Estado, [...] "as máquinas, as descobertas científicas, o sistema governamental são testemunhas de uma certa estrutura de relações humanas, da sociedade, de um modo determinado de comportamento humano" " (ELIAS, 1973, p. 128). A legitimação desse problema diz respeito à relação do Estado com os indivíduos que abordamos agora. Gradualmente, o tema "imigração" passa a ser relacionado a casos chamados de "violência urbana" que são socialmente definidos pela associação entre atos de violência em periferias por jovens descendentes de imigrantes.

Em julho de 2010, um outro caso de violência urbana chama a atenção das autoridades e jornalistas. Um grupo de moradores da Villeneuve incendiaram carros e trocaram tiros com a polícia, após a morte de um jovem, Karim Boudouda, um descendente de imigrantes e residente local. Após a violência, o governo de Nicolas Sarkozy toma várias medidas, principalmente em termos de segurança: o ministro do Interior, Brice Hortefeux anuncia o envio de reforço de forças móveis e um helicóptero para Grenoble; o Presidente Nicolas Sarkozy anuncia a criação de novos dispositivos policiais, o GIR (Grupo de Intervenção Regional) e a UMIR (Unidade de Intervenção Rápida Mista).

Em uma conferência de imprensa, o Presidente associa diretamente os problemas relativos às periferias francesas ao fluxo imigratório para o país. O discurso de Nicolas Sarkozy se focaliza sobre a relação entre a imigração, a violência e a insegurança encontradas no país, como demonstra um trecho do seu discurso: "Devemos reconhecer, eu tenho que dizer, nós sofremos as consequências de 50 anos da imigração insuficientemente regulamentada que levaram a uma falta de integração (...) A guerra que eu decidi começar

4 “[...] les machines, les découvertes scientifiques, le système gouvernemental sont les témoins d'une certaine structure des rapports humains, de la société, d'un mode déterminé du comportement humain". 
contra os traficantes, contra os bandidos, essa guerra vale por vários anos $5 \%$. (SARKOZY, 2014). O fluxo migratório "não controlado" é interpretado como a causa principal dos problemas atuais que o país deve enfrentar, como o tráfico de drogas e a violência. De uma parte, os problemas são apresentados como específicos das periferias, de outra parte, como problemas relacionados aos imigrantes.

Durante a sua ida a Grenoble no final de julho de 2010, o Presidente da República, Nicolas Sarkozy, propõe uma mudança no Código Penal, sugerindo a remoção de cidadania francesa dos indivíduos que cometem uma infracção penal. Dessa maneira, um item adicional ao projeto de lei chamado "Imigração, Integração e Nacionalidade" foi desenvolvido alguns meses depois de sua declaração.

O Código Civil francês permite a retirada da nacionalidade francesa, mas em casos específicos, como o terrorismo e os crimes de guerra. O chefe de Estado propõe dessa forma a extensão das possiblidades de privação da nacionalidade. A emenda sobre a retirada da nacionalidade significa que, se adotada, as sanções devem ser ajustadas a cada pessoa que comete um crime contra as forças de ordem, o que torna mais evidente a oposição entre "franceses" e "imigrantes". Com essa proposta, o Presidente faz referência aos franceses de origem estrangeira, como é caso de Karim Boudouda, morto na Villeneuve, que era filho de argelinos. O discurso do Presidente diz respeito a grupos que, independente de sua nacionalidade, são vistos como imigrantes. Dessa maneira, tudo indica que a origem dos indivíduos representa uma ameaça.

Dessa forma, os jovens de origem estrangeira são apresentados como responsáveis da "crise" das periferias. Nesse sentido, a reação do Estado na elaboração da emenda contribui para a estigmatização do imigrante e de descendentes de imigrantes. Como define Erving GOFFMAN (1975), um estigma é um atributo que é socialmente designado a certos indivíduos tornando-os diferentes dos outros membros da sociedade: ele designa " um atributo que lança um descrédito profundo" ou uma "má reputação" a determinadas pessoas (1975, p.13). Além disso, o chefe de Estado faz declarações inexatas a propósito da imigração na França e sobre a população que habita zonas urbanas sensíveis (ZUS), o que compromete a compreensão do fenômeno migratório no país. Ora, a relação entre descendente de imigrante e as áreas residenciais das ZUS, assim como a relação entre essas zonas, os descendentes de imigrantes e os jovens magrebinos não é evidente como aparenta ser. Um descendente de

\footnotetext{
5 "Il faut le reconnaître, je me dois de le dire, nous subissons les conséquences de cinquante années d'immigration insuffisamment régulée qui ont abouti à un échec de l'intégration. La guerre que j'ai décidé d'engager contre les trafiquants, contre les voyous, cette guerre-là vaut pour plusieurs années ».
} 
imigrante não mora obrigatoriamente nas zonas urbanas sensíveis. O número de imigrante nessas zonas é mais importante que o número de descendentes de imigrantes. Um descendente de imigrantes não significa uma pessoa jovem ou menor de idade, porque uma pessoa descendente de imigrantes nascida na França (de ao menos um pai imigrante) continua sendo descendente de imigrantes para o resto da vida. Além disso, a população de descendentes de imigrantes é fundamentalmente vinda de fluxos migratórios antigos, vindos de Portugal, da Itália e da Espanha. Cerca de $65 \%$ dos descendentes são originários da Europa. Os descendentes do Maghreb representam 23\%. No entanto, no caso de descendentes de 15-24 anos o Magrebe representa 36\% das origens (BREEM, 2010).

Ademais, no discurso do chefe de Estado, o tema "imigração" aparece como o problema mais importante da Villeneuve, deixando em segundo plano as formas locais de exclusão e as particularidades dessa área. Nesse sentido, a postura do Estado é uma postura que quer passar uma mensagem que tranquilize os cidadãos, porque ela engloba o indivíduo em um grupo: o grupo dos imigrantes. Fazendo isso, ela exclui toda a marginalidade que existe na França e a desigualdades observadas nessa zona urbana e na cidade de Grenoble. A Villeneuve faz parte da zona urbana sensível da aglomeração de Grenoble, uma zona prioritária em termos de política urbana. Os indicadores de precariedade (o número de desempregados, de famílias monoparentais, de beneficiários de uma alocação de residência) se concentram na parte sul de Grenoble, onde se encontra a Villeneuve (BERTHELOT, 2008). Essa parte é caracterizada por uma forte proporção de população estrangeira. A zona urbana sensível da aglomeração conta com 17.732 habitantes sendo que 15, 3\% são estrangeiros. Grenoble apresenta 158746 habitantes sendo 9,3\% de estrangeiros, segundo a análise realizado pela Insee em 2008. Entretanto, a Villeneuve é composta por vários conjuntos habitacionais muito heterogêneos: são 23 que reagrupa um total de 4200 residências e 10.700 moradores de acordo com o recenseamento de 1999 (HABITER, 2003). Devido à heterogeneidade da Villeneuve, é como se houvesse várias e não apenas "uma" Villeneuve. Além disso Grenoble é uma cidade onde os indicadores de precariedade passam as fronteiras das periferias contempladas pela política urbana. O antigo centro de Grenoble também apresenta sinais de precariedade financeira e ligada ao emprego (BERTHELOT, Alain, 2008).

Nesse sentido, o Estado tenta impor, portanto, uma definição dos incidentes, reforçando os aspectos socialmente acordados ao "problema da imigração". Eles se traduzem pela relação entre imigração e casos de violência ocorrendo em periferias. O imigrante aparece como o "culpado" no discurso de Nicolas Sarkozy. Dessa forma, o Presidente 
interpreta os incidentes como o resultado de uma relação de oposição entre a sociedade francesa e os imigrantes e os filhos de imigrantes. A oposição, tal como é apresentada pelo chefe de Estado, revela "sinais distintivos" da "superioridade" dos padrões ocidentais de comportamento diante do comportamento dos imigrantes, principalmente do imigrantes dos países do Maghreb já que o jovem em questão é Karim Boudouda, filho de argelinos. Nesse sentido, durante os incidentes na Villeneuve, Nicolas Sarkozy inscreve a questão da imigração na esfera privada, culpando os imigrantes pelos atos de violência cometidos nessa área residencial. As questões políticas relacionadas à imigração e aos bairros prioritários (tais como, por exemplo, as precárias condições de vida dos habitantes) são reduzidas por um representação consensual dos aspectos do problema: a concentração de imigrantes nos subúrbios e o comportamento violento dos "jovens imigrantes”.

Essa postura não foi uma postura adotada momentaneamente, em razão dos incidentes em Grenoble. Como já abordado, durante campanha presidencial de Nicolas Sarkozy, no início dos anos 2000, a imigração foi apresentada como uma questão de interesse geral. O suposto interesse (ou melhor, a suposta preocupação) dos cidadãos em relação a esse problema é, portanto, apresentado como um argumento para legitimar a tomada das decisões políticas em matéria de imigração.

A urgência anunciada para o tratamento dessa questão é ainda mais visível quando Nicolas Sarkozy apresenta os resultados da política de imigração desde 2002 (Conferência de imprensa sobre a imigração, Paris, 11 de dezembro de 2006). Ele fala em nome do interesse dos franceses em relação ao tema imigração. Seu argumento se apoia nos resultados de uma enquete publicada na imprensa em 2005, como testemunha a seguinte passagem:

Uma sondagem publicada no Le Monde em dezembro de 2005 mostra que $63 \%$ dos franceses estimam que tem imigrantes demais na França. 50\% dos eleitores da esquerda concordam com essa observação. Eu estou convencido que a imensa maioria de nossos compatriotas não são nem racistas nem xenófobos (LE DISCOURS, 2010).

Criticando o fracasso das políticas anteriores, ele reforça a sua posição sobre a política de imigração. O interesse de Nicolas Sarkozy pela política de imigração vem desde o início de 2000, quando ele era ministro do Interior (2002-2007). Em 2003, por exemplo, na votação do projeto de lei na Assembleia Nacional relativo ao controle e à estadia dos estrangeiros na França, ele afirma que "A imigração é uma das questões sociais, onde a confiança dos nossos concidadãos no Estado é mais fragilizada"(SAZKOZY, 2003). Nos anos seguintes, a importância da questão imigração é fortalecida. Ela é apresentada por Nicolas Sarkozy como 
“questão decisiva para os próximos anos (SARKOZY, Nicolas. Je ne peux laisser passer. Libération, 5 de agosto 2005); como uma dificuldade ou ainda como uma prioridade: "o uso generalizado de vistos biométricos, a deportação de imigrantes ilegais, o rigor em relação aos países de onde surgem fluxos ilegais, são agora as principais prioridades do governo" (SARKOZY, 2005). Esse posicionamento fica evidente no momento dos incidentes na Villeneuve que tratamos em seguida.

\subsection{O "nacional" e o "local" em relação aos incidentes na Villeneuve}

No momento dos incidentes na Villeneuve, enquanto Nicolas Sarkozy anuncia novas medidas para essa área residencial, como a criação do GIR (Grupo de intervenção regional), no nível local, o prefeito de Grenoble, Michel Destot (Partido Socialista), destaca a falta de comprometimento do Estado com a política urbana. Alguns dias depois da morte de Karim Boudouda na Villeneuve e os atos de violência, a municipalidade organiza uma reunião com 30 atores locais onde o prefeito se engaja na aceleração da política urbana. A ênfase é dada nas questões de segurança e de promoção da coesão social. Michel Destot relembra o montante do investimento do município na Villeneuve (75 milhões de euros investidos em sua renovação) e minimiza os incidentes através dessa declaração que destaca o valor da cidade: “Grenoble e sua aglomeração oferecem vantagens" (NOUS allons accélérer les politiques de la Ville. Le Dauphiné Libéré, 21 de julho de 2010). O prefeito critica as iniciativas imediatistas do Estado (como, por exemplo, a mobilização temporária de reforço da polícia) e defende as medidas implementadas a longo prazo, especialmente porque outros atos de violência já foram cometidos na Villeneuve. Em dezembro de 2000, houve a morte de Soufiane, 15 anos, assassinado por outros jovens também na Villeneuve (CABRET, Le Monde, 2000). Em 2007, um controle do tráfico de drogas resulta na confrontação de dois grupos que pertencem a Villeneuve (Le Monde, 3 de novembro de 2007; Le Monde, 7 de dezembro de 2007).

Em várias ocasiões, o prefeito se posiciona contra as declarações do Presidente da República e do Ministro do Interior, Brice Hortefeux, sobre a "guerra contra os bandidos" e a delinquência. Michel Destot diz querer a "paz social” e promover diálogo entre a polícia e os moradores da Villeneuve. A ênfase é dada à coesão social e ao "agir em conjunto": Estado, municípios e associações. 
O dia da chegada do presidente na cidade, o prefeito de Grenoble insiste em destacar as características da Villeneuve e a presença policial constante nessa área. A Villeneuve é apresentada na imprensa como um local propício para o encontro dos moradores por causa de espaços comuns, como por exemplo o "Espaço 600" que é um teatro regional, localizado na galeria do Harlequin (um dos complexos residenciais na Villeneuve). Para Michel Destot, prefeito de Grenoble durante quinze anos (1995 -2014), trata-se de mostrar que a área não tem sido negligenciada durante seus três mandatos. Ele denuncia a estigmatização do bairro, da cidade e de seus habitantes pelo tratamento dos incidentes pelo Estado. Em um artigo publicado no jornal regional Le Dauphiné Libéré, o prefeito afirma sobre a Villeneuve:

Não se trata de uma área residencial abandonada. A Villeneuve é um dos lugares de Grenoble melhor dotados em termos de equipamentos sociais, culturais, de saúde. [...]. É o mais bem equipado em termos de polícia municipal. De todas as áreas, é o mais novo e menos dilapidado. Precisamos experimentar e inovar, especialmente se temos um problema de precariedade (DESTOT, 2010. Tradução nossa).

O prefeito acredita que as ações tomadas pelo Estado são exageradas, pois foram apenas algumas pessoas (ao todo são 12.000 moradores) que enfrentaram a polícia. Além disso, o prefeito relembra que os acontecimentos na Villeneuve não são um caso isolado: ele cita exemplos de violência que ocorreram em outras cidades na França, como em Toulouse e Paris. O prefeito tenta, dessa forma, valorizar as ações locais recentes desenvolvidas na Villeneuve. Quanto mais o prefeito destaca a falta de comprometimento do Estado, mais ele promove as ações locais nas áreas de intervenção da política urbana, tais como, por exemplo, a renovação urbana, a mediação social ou a segurança. O "convívio" e a "imagem" da Villeneuve a nível nacional são as palavras de ordem do prefeito a cada intervenção pública e, em particular, em resposta às declarações de Nicolas Sarkozy. No entanto, a posição do prefeito em relação à ação do Estado não é apresentada como um posicionamento político partidário: um prefeito socialista diante de um governo de direita. Essa postura não se revela abertamente, porém, revela uma orientação política partidária.

Enquanto o presidente propõe a retirada da nacionalidade das pessoas de origem estrangeira que tenham cometido crimes contra as forças de segurança, a municipalidade de Grenoble municipal revela o ideal universalista francês que se baseia na noção de igualdade dos cidadãos. A municipalidade apresenta a cidade de Grenoble como uma cidade cosmopolita, de integração, dinâmica e "aberta", como podemos observar na revista de informação municipal chamada "Les Nouvelles de Grenoble" (Figura 2). Segundo notícias 
publicadas em jornais do nosso corpus ${ }^{6}$, essas características sao indícios da modernidade da cidade, relacionadas à tradição política socialista implementada em Grenoble pelo antigo prefeito Hubert Dubedout, entre 1965-1983. Grenoble é a cidade referência do "laboratório político da esquerda" (GRENOBLE, 1998). Portanto, um modelo do socialismo municipal.

O diretor do gabinete do atual prefeito, assim como um antigo diretor de comunicação da municipalidade de Grenoble ${ }^{7}$ reforçam essa observação sobre a cidade ser cosmopolita, afirmando que a diversidade das pessoas que moram em Grenoble - frequentemente vindas de outros departamentos e regiões, mas também de outros países - faz a especificidade dessa cidade. Grenoble conta com um número importante de pessoas nascidas em outras cidades francesas e muitos estudantes estrangeiros ${ }^{8}$ (BONNET; MUSTAPHA, 2013). Assim, podemos observar que, através de práticas de comunicação, o prefeito visa dar sentido para ação municipal. Nessa lógica, ser prefeito não é "apenas" implementar instalações ou desenvolver projetos urbanos na cidade. Trata-se de tornar os cidadãos orgulhosos da sua cidade. Como afirma o pesquisador Philippe Garraud, a ação da municipalidade visa se "fazer conhecer, fazer significar e fazer ver" (GARRAUD, p.14). O reconhecimento exterior (nacional) da ação local é também procurado pelo poder local. Para isso, o serviço de imprensa da municipalidade de Grenoble foca preferencialmente na agência de notícias, AFP (Agence France-Presse). Encontros com jornalistas em Paris também são previstos ${ }^{9}$.

Em relaçao à Villeneuve, a postura da municipalidade se direciona para o que contribui para a coesão entre os moradores, tornando invisível o imigrante enquanto ator social. Quando o prefeito comenta os incidentes, ele não fala da presença de imigrantes ou descendentes de imigrantes nas periferias. Ela prefere invisiblizar essa questão. Isso pode ser explicado pelo modo de apreensão da periferia pela municipalidade. As zonas urbanas sensíveis são tidas como lugares onde a municipalidade visa desenvolver projetos que priorizem a coesão social: a Villeneuve é tida como um lugar do convívio entre diferentes modos de vida. Um dos projetos criados no bairro foi o do canal de televisão local, nos anos 70, concebido como um lugar de expressão para os habitantes, que poderia desempenhar um papel importante no estabelecimento e fortalecimento das relações entre os moradores. Isso se

\footnotetext{
6 Como exemplo, citamos: GARIN, Christine. Le nouveau Virage de la cité des sciences. Le Monde, Décryptages Villes, 3 de junho de 2009 ; VILLE symbolique de la décentralisation, Grenoble réinvente les conseils consultatifs de secteur. Le Monde, 14 de fevereiro de 2002.

${ }^{7}$ Entrevistas realizadas respectivamente nos dias 6 de março de 2012 e no dia 27 de maio de 2011.

${ }^{8} \mathrm{O}$ número de estudantes estrangeiros, por exemplo, chega a $10.6 \%$ da população. É umas das proporções maiores do país.

${ }^{9}$ Motte Céline, assessora de imprensa da prefeitura de Grenoble. Entrevista realizada no dia 11 de janeiro de 2012.
} 
deve à própria história de construção do bairro nos anos 60 e 70. Villeneuve é o símbolo da diversidade social (Joly, 1995) e designado pelo poder local como o lugar do multiculturalismo.

Se a questão da imigração é um problema público, ela não é, no entanto, tida como um problema político pela municipalidade. A dimensão propriamente política das periferias como por exemplo, as desigualdades sociais entre imigrantes e franceses - não são colocadas em evidência pelo prefeito.

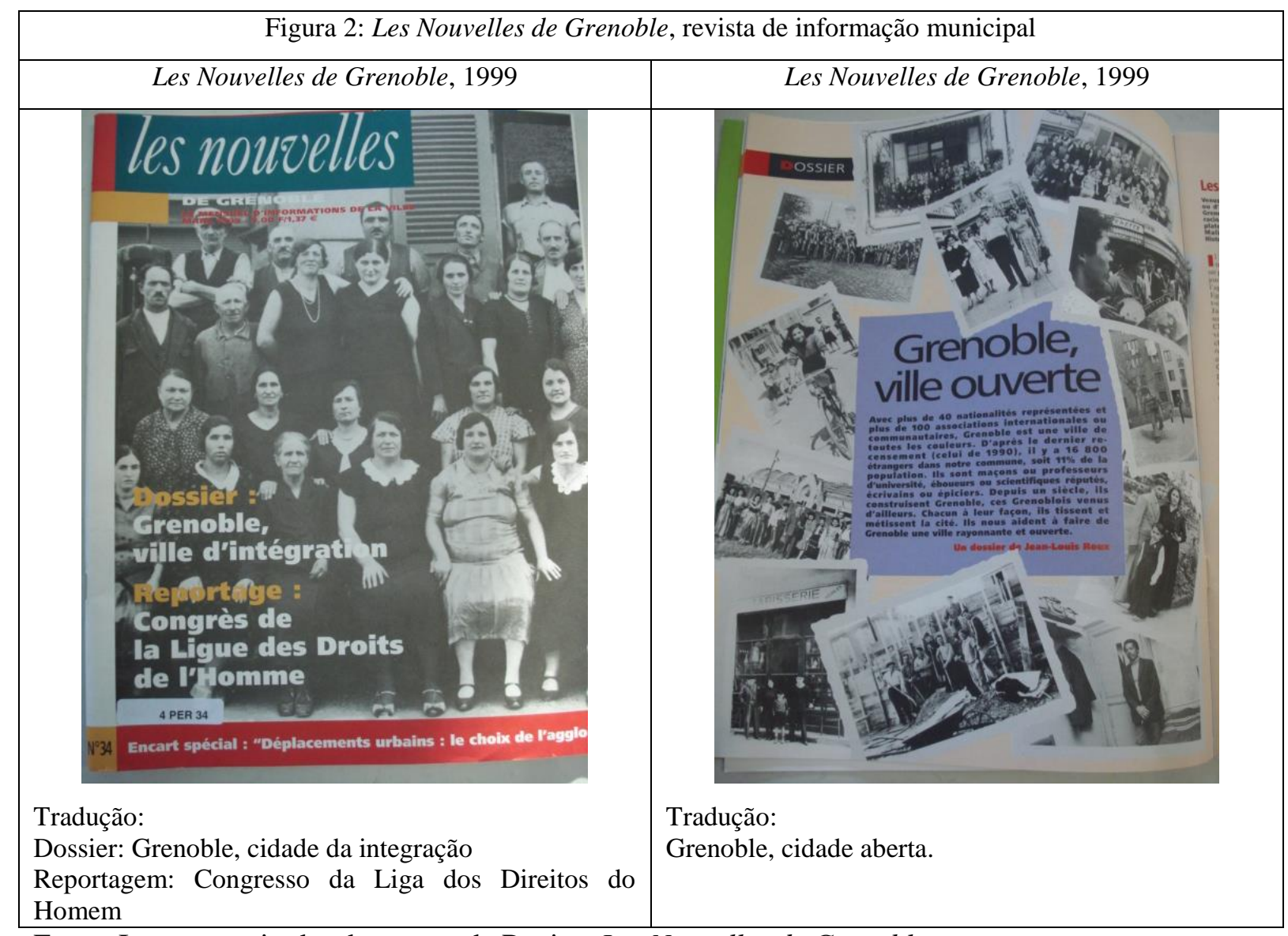

Fonte: Imagens retiradas do acervo da Revista Les Nouvelles de Grenoble.

A análise das posições de chefe de Estado e do prefeito de Grenoble, no momento dos incidentes na Villeneuve mostra a localização do problema nos territórios, porque ele está vinculado, de acordo com o Chefe de Estado, a códigos de comportamento. Nessa lógica de localização do problema, o "subúrbio" é o lugar do desenvolvimento de projetos culturais que priorizam a coesão social. O centro da cidade, ao contrário, é o lugar da política e da inovação. 
A ida do Presidente à cidade de Grenoble revela uma intenção política partidária, mesmo que ela não tenha sido abertamente exposta na mídia. Essa atitude reflete uma forte vontade política de reforçar a restrição das leis existentes sobre as condições de entrada e residência de estrangeiros e imigrantes no país. A partir dos anos 70, a política de imigração se torna mais restrita (WEIL, 2005). Assim, as decisões políticas tomadas no momento dos acontecimentos em Villeneuve devem ser entendidas em um período de tempo longo.

\section{CONSIDERAÇÕES}

As questões políticas ligadas à imigração e às periferias (como, por exemplo, a precariedade das condições de vida dos moradores) são reduzidas por uma representação consensual dos aspectos dos problemas que afetam as zonas urbanas sensíveis. As desigualdades sociais do país são deixadas de lado. O Presidente da República, no momento dos incidentes na Villeneuve atribui a responsabilidade dos incidentes aos imigrantes, contribuindo para a diferenciação social entre franceses e imigrantes.

Os resultados nos levam a conclusão de que o "problema da imigração" não é um problema propriamente político: a maneira como ele é definido pelos responsáveis políticos responsabiliza os indivíduos ao invés de oferecer explicações mais estruturais do problema. Pode-se concluir que a definição do Estado do "problema da imigração" repousa na "ameaça" que esse assunto representa para os cidadãos franceses em termos de emprego e de coesão social. Na época dos incidentes na Villeneuve, o posicionamento político do chefe de Estado no que diz respeito ao tema torna-se evidente: ele impõe uma definição dos incidentes reforçando os aspectos socialmente acordados ao "problema dos imigrantes". Esses aspectos refletem a relação entre imigração e casos de violência em periferias. Apesar do desentendimento aparente entre o Presidente e o prefeito, o discurso do chefe de Estado é um discurso sem oposição dos poderes públicos locais e termina por silenciar qualquer conflito a nível local. Dessa forma, as práticas infocomunicacionais sobre a imigração aparecem como uma ferramenta governamental que contribui para imposição de um enquadramento sobre o problema da imigração e, por consequência, a regulação da esfera pública. Notadamente, diante do silêncio dos poderes locais face ao posicionamento do Presidente. Ambos contribuem para a despolitização da questão da imigração, negligenciando a dimensão estrutural do "problema". 
O foco é o indivíduo e não a discussão pública sobre a sociedade e suas desigualdades. Localmente, a questão da imigração é invisibilizada em detrimento da valorização das riquezas culturais presentes na cidade e, especialmente, nas áreas prioritárias da política urbana. Grenoble é apresentada na mídia como o lugar tradicionalmente da democracia local.

\section{REFERÊNCIAS}

A GRENOBLE. Gitans » et « Maghrébins » s'affrontent pour le marché de la drogue. Le Monde, 7 de dezembro de 2007.

ARTIGO adicional ao projeto de lei "Immigration, Intégration et Nationalité", 20 de setembro de 2010, IN: Assembleia Nacional, URL: http://www.assemblee-nationale.fr/, consultado no dia 15 de abril de 2012.

BACHMANN, Christian; LEGUENNEC, Nicole. Violences urbaines. Ascension et chute des classes moyennes à travers cinquante ans de politiques de la ville. Paris: Editions Albin Michel, 1996.

BARATS, Christine. L'intégration et le discours présidentiel sur l'immigration : inscription dans l'espace national et consensus d'évitement. Quaderni, n² 22, 1994, p. 109-123.

BERGER, Peter, Luckman Thomas (1966). La construction sociale de la réalité. Paris: Armand Colin, 2012.

BERTHELOT, Alain. Précarité dans l'agglomération de Grenoble: pas uniquement dans les zones urbaines sensibles. La Lettre Analyses, n 99 , 2008, sur www.insee.fr/rhonealpes.).

BONNAFOUS, Simone. L’immigration prise aux mots. Paris: Editions Kimé, 1991.

BONNET, Michel; MUSTAPHA, Touahir. Lyon et Grenoble: deux profils métropolitains différents. La Lettre-Analyse. Insee Rhône-Alpes, n 206, décembre 2013.

BOURDIEU, Pierre (1984). Questions de sociologie, Paris : Les Editions de minuit, 2002.

BOUVIER, Gérard. Les descendants d'immigrés plus nombreux que les immigrés: une position française originale en Europe. Insee Références. 2012.

BREEM, Yves. Les descendants d'immigrés. Info migrations, ${ }^{\circ}{ }^{15}$, juillet 2010.

CABRET, Nicole. Soufiane, quinze ans, a été tué à Grenoble par deux mineurs de seize et dix-sept ans, Société. Le Monde, 5 de dezembro de 2000.

CHAMPAGNE, Patrick. La construction médiatique des «malaises sociaux. Actes de la recherche en sciences sociales, $n^{\circ}$ 90, 1991, p.64-76.

COLLOVALD, Annie. Des désordres sociaux à la violence urbaine. Actes de la recherche en sciences sociales, $\mathrm{n}^{\circ}$ 136-137, 2001, p.104-113. 
DE SOUZA PAES, Paula. La communication publique et les pratiques journalistiques au prisme des mutations sociales: la question de l'immigration en France (1980-2010). 2014. 486f. Tese (Doutorado em ciências da informação e da comunicação) - Universidade Grenoble 3-Stendhal, Grenoble, 2014.

DESTOT: « Je ne laisserai stigmatiser ni Grenoble ni la Villeneuve. Le Dauphiné Libéré. 30 de julho de 2010.

DUBEDOUT, Hubert. Ensemble, refaire la ville: rapport au Premier ministre du Président de la Commission nationale pour le développement social des quartiers. Paris: La documentation française, 1983.

ELIAS, Norbert (1969). Civilisation des mœurs. Paris: Calmann Lévy, 1973.

ELIAS, Norbert. La dynamique de l’Occident, Paris, Calmann-Lévy, 1975.

GARRAUD, Philippe. Discours des maires et construction locale du politique. Mots, $\mathrm{n}^{\mathrm{o}} 25,1990$, $\mathrm{p}$. 7-21.

GRENOBLE : la grande politique des petits travaux. Le Monde, 12 de junho de 1998.

GOFFMAN, Erving. Stigmate. Les usages sociaux des handicaps. Paris: Les Editions de Minuit, 1975.

GRENOBLE en proie à une vendetta meurtrière entre trafiquants de drogue. Le Monde, 3 de novembro de 2007.

HABITER et vivre à la Villeneuve, diagnostic. Municipalité de Grenoble, março de 2003. Diponível em : http://infovn.free.fr/documents/03-042_villeneuve.pdf. Acesso em : 26 de janeiro de 2017.

JOLY, Jacques; PARENT, Jean-François. Grenoble de 1965 à 1985. Paysage et politique de la ville. Grenoble: PUG, 1988.

LA HAYE, Yves (de). Dissonances. Critique de la communication. La pensée sauvage, 1984.

LAFARGE, Géraud. La double construction de la sociologie de l'exclusion. Regards Sociologiques, $\mathrm{n}^{\circ} 23,2002, \mathrm{p} .59-74$.

LE DISCOURS de Grenoble de Nicolas Sarkozy. Le Figaro, 30 de julho de 2010, artigo atualizado no dia 31 março de 2014.

NEVEU, Erik. L'approche constructiviste des «problèmes publics », un aperçu des travaux anglosaxons. Questions de communication, n²2, 1999, p. 41-57.

NOUS allons accélérer les politiques de la Ville. Le Dauphiné Libéré, 21 de julho de 2010.

OLLIVIER-YANIV, Caroline. L'Etat communiquant, Paris, PUF, 2000.

PITTI, Laure. Grèves ouvrières versus luttes de l'immigration: une controverse entre historiens.

Ethnologie française, $n^{\circ} 31,2001$, p.465-476.

PITTI, Laure. "Travailleurs en France, voilà notre nom". Les mobilisations des ouvriers étrangers dans les usines et les foyers durant les années 1970. IN: BOUBEKER, Ahmed, HAJJAT, Abdellali (coord.). 
Histoire politique des immigrations (post) coloniales France, 1920-2008. Paris: Editions Amsterdam, 2008, p. 95-111.

SARKOZY, Nicolas. Conférence de presse sur l'immigration. Paris, le 11 décembre 2006.

Disponivel: http://www.interieur.gouv.fr/Archives/Archives-de-Nicolas-Sarkozy-2005-

2007/Interventions/11.12.2006-Conference-de-presse-sur-l-immigration. Acesso em: 13 julho 2013.

SARKOZY, Nicolas. Projet de loi relatif à la maîtrise de l'Immigration et au séjour des étrangers en France 2003. Ministère de l'Intérieur, URL: http:// www.interieur.gov.fr, consultado no dia 10 de dezembro de 2012.

SARKOZY, Nicolas. Je ne peux laisser passer. Libération, 5 de agosto 2005.

SOLE, Robert. Les candidats et l'immigration. Le Monde. 23 de março de 1988.

VIGNA, Xavier, « Une émancipation des invisibles? Les ouvriers immigrés dans les grèves de maijuin 68 », dans: Boubeker Ahmed, Hajjat Abdellali (coord.). Histoire politique des immigrations (post) coloniales, France, 1920-2008. Paris, Editions Amsterdam, 2008.

WEIL, Patrick. La République et sa diversité. Immigration, intégration, discriminations. Paris: Editions du Seuil et la République des Idées, 2005.

\section{Original recebido em: 27 de janeiro de 2017}

Aceito para publicação em: 02 de novembro de 2017

Paula de Souza Paes

Mestre e Doutora pela Universidade Grenoble-Alpes (França).

Ganhou o prêmio de Tese em 2015 pela Escola Doutoral da Université de Grenoble-Alpes.

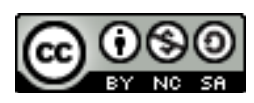

Esta obra está licenciado com uma Licença

Creative Commons Atribuição-NãoComercial-CompartilhaIgual 4.0 Internacional 